\title{
Idiopathic obstructive eosinophilic enteritis with raised IgE: response to oral disodium cromoglycate
}

\author{
N. H. GILINSKY \\ M.B.Ch.B. (U.C.T.), M.R.C.P. (U.K.). \\ R. E. KotTLER \\ M.B.Ch.B., M.Med. (Rad. D.) \\ Gastrointestinal Clinic and the Departments of Medicine and Radiology, Groote Schuur Hospital, \\ University of Cape Town, Observatory, Cape Town, South Africa
}

\begin{abstract}
Summary
A 65-year-old man with a 20-year history of recurrent abdominal pain and vomiting was found to have eosinophilic enteritis affecting the muscularis layer of the distal ileum. Tests for malabsorption were negative. The IgE was raised but there was no evidence of an allergic predisposition. The symptoms, eosinophilia, and radiological abnormality responded to oral disodium cromoglycate.
\end{abstract}

\section{Introduction}

Eosinophilic gastroenteritis is an uncommon disease characterized by peripheral eosinophilia and eosinophilic infiltration of the gastrointestinal tract. The bone marrow shows a reactive eosinophilia and the symptoms and signs usually reflect the layer of bowel which is most severely affected. Predominant mucosal disease may be associated with malabsorption, muscle disease with obstructive symptoms and serosal disease with ascites. Laparotomy may be necessary to substantiate a diagnosis or to relieve obstruction. Corticosteroid therapy has been the most specific medication used while elimination diets have proved unsuccessful. This report is of a patient with clinical and histological evidence of eosinophilic enteritis involving the muscularis layer of bowel which responded to oral disodium cromoglycate.

\section{Case report}

A 65-year-old male was referred in 1981 for evaluation of recurrent abdominal pain. It had first begun in 1960, was situated in the upper abdomen and associated with vomiting. A barium meal failed to demonstrate peptic ulcer disease. The pain settled eventually after a few months but recurred in 1964. A repeat barium meal was negative and an enzyme-stimulated pancreatic function test, done in view of the episodic nature of the pain with intermittent radiation to the back, was also normal. There were recurrences in 1967 and 1973. On these occasions the pain was situated in the right iliac fossa, was cramp-like and was accompanied by vomiting and diarrhoea.

In 1974 a barium follow-through demonstrated thickened folds in the terminal ileum. The haemoglobin was $12.5 \mathrm{~g} / \mathrm{dl}$ and the ESR was $18 \mathrm{~mm} / \mathrm{hr}$. There was an absolute eosinophilia of $2.744 \times 10^{9} / 1$. No evidence of parasitic infection could be found. In 1978 upper gastrointestinal endoscopy and a sigmoidoscopy, done after another episode of pain, were normal. Abdominal ultrasound, intravenous pyelogram and an oral cholecystogram done during three further bouts were normal. An admission abdominal radiograph in 1981 demonstrated localized air-fluid levels in the right upper quadrant.

There was no personal or family history of allergy and no drug ingestion of note. The exacerbations were not associated with a pyrexia or skin rash and at no stage were the stools positive for occult blood. Dietary review revealed no specific food intolerance. Examination revealed no stigmata of Crohn's disease, polyarteritis nodosa or lymphoma. The abdomen was slightly distended without free fluid being present. The bowel sounds were active. The Mantoux test was negative.

\section{Investigations}

Hb $12.6 \mathrm{~g} / \mathrm{dl}$; WBC $9.5 \times 10^{9} / 1$; eosinophil count $3.515 \times 10^{9} / \mathrm{l}$; ESR $57 \mathrm{~mm} / \mathrm{hr}$ (Westergren). The bone marrow revealed prominent eosinophil precursors but was otherwise normal.

Plasma urea, electrolytes, calcium, phosphate, creatinine, cholesterol and liver transaminases were within normal limits. The total serum protein was $71 \mathrm{~g} / \mathrm{l}$ and serum albumin $36 \mathrm{~g} / \mathrm{l}$. The serum alkaline phosphatase was $150 \mathrm{mmol} / \mathrm{l}$ and was of bowel and liver origin.

At endoscopy, the stomach and upper small bowel appeared normal and biopsies from these areas were normal. There were no parasites in the jejunal aspirate. Sigmoidoscopy and a rectal biopsy were normal. The stools did not contain CharcotLeyden crystals, parasites or pus cells and bacteriology was negative. 
A Schilling's test, 72-hr faecal fats, D-xylose excretion, glucose tolerance test, lactose breath test, serum iron, folate, vitamin $B_{12}$ and a prothrombin index were all normal.

Alpha chains, Yersinia antibodies, hepatitis B virus antigen and antibody tests were negative. Protein electrophoresis, IgG, IgA and IgM were normal. The IgE radio-immunoassay (Phadebas, Pharmacia) was $1304 \mathrm{mu} . / 1$. (normal $<150 \mathrm{mu}$./l) Intradermal skin tests to 7 inhaled and 25 ingested antigens were negative. Radio-allergosorbent(RAST) tests for specific IgE antibodies to milk, egg white, wheat and fish were negative.

The chest radiograph was normal. A barium follow-through (Fig. 1) revealed an abnormal distal ileum with a thickened wall and consequent narrowed lumen. The folds were swollen without mucosal ulceration.

\section{Subsequent course}

A repeat eosinophil count after a course of anthelminthic therapy was $3.696 \times 10^{9} / 1$. A fulle. thickness ileal biopsy was done to substantiate $a=$ diagnosis of eosinophilic enteritis. At laparotomy there was no ascites or lymphadenopathy. The large듣 bowel appeared normal but the distal ileum was markedly thickened and rigid. The mucosa, visual- $\frac{\bar{D}}{\vec{D}}$ ized via a small sigmoidoscope passed through an尺 enterotomy, appeared normal. Full thickness ilealø biopsy revealed a normal villous pattern and cellpopulation. However, the muscularis mucosa contained a dense infiltrate of eosinophils and the $\vec{\omega}$ muscle fibres were splayed by a mild interstitial $\Omega$ oedema (Fig. 2). A skeletal muscle biopsy revealedo no evidence of arteritis and the only abnormality 3 . in a needle liver biopsy was occasional eosinophils ${ }_{\infty}^{\circ}$ in the portal tracts.

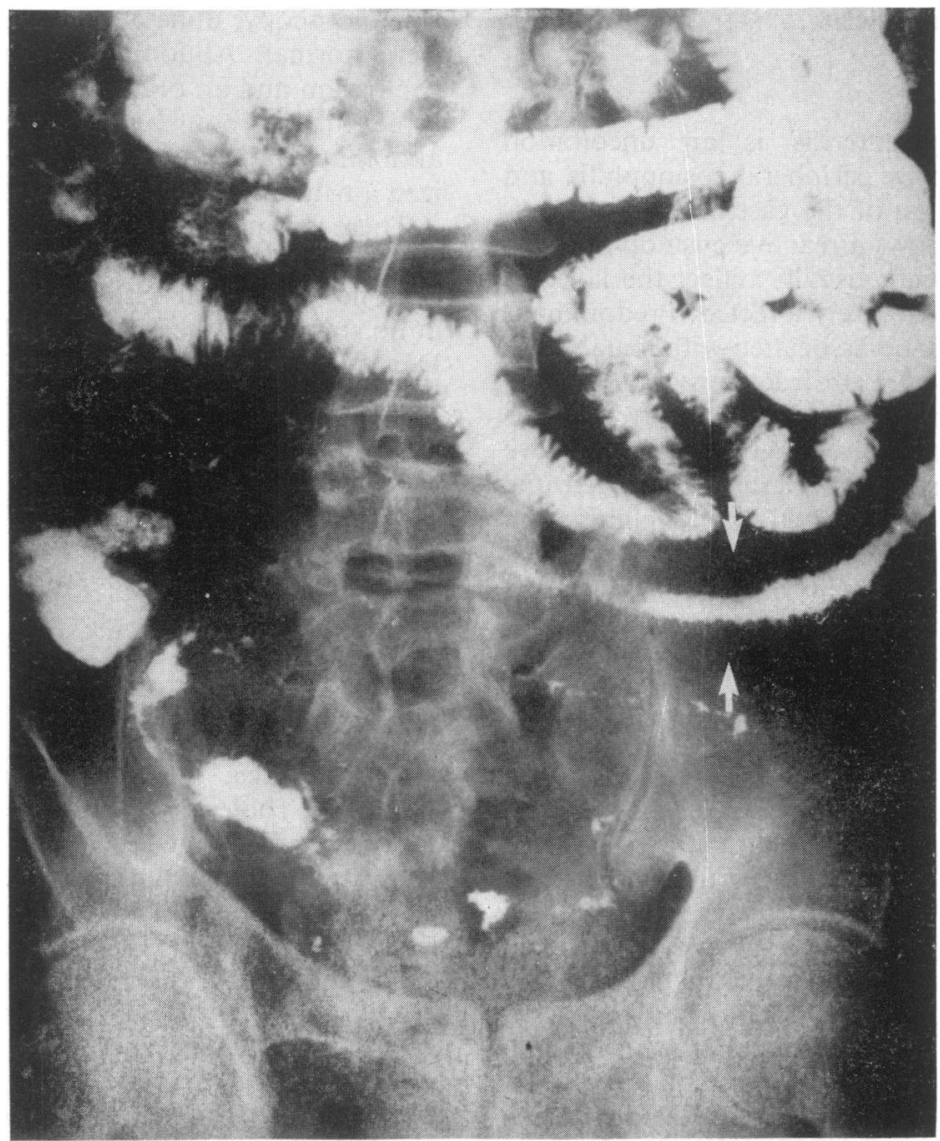

Fig. 1. Widespread distal ileal abnormality consisting of thickened walls (arrowed), swollen folds and narrowed lumen. 


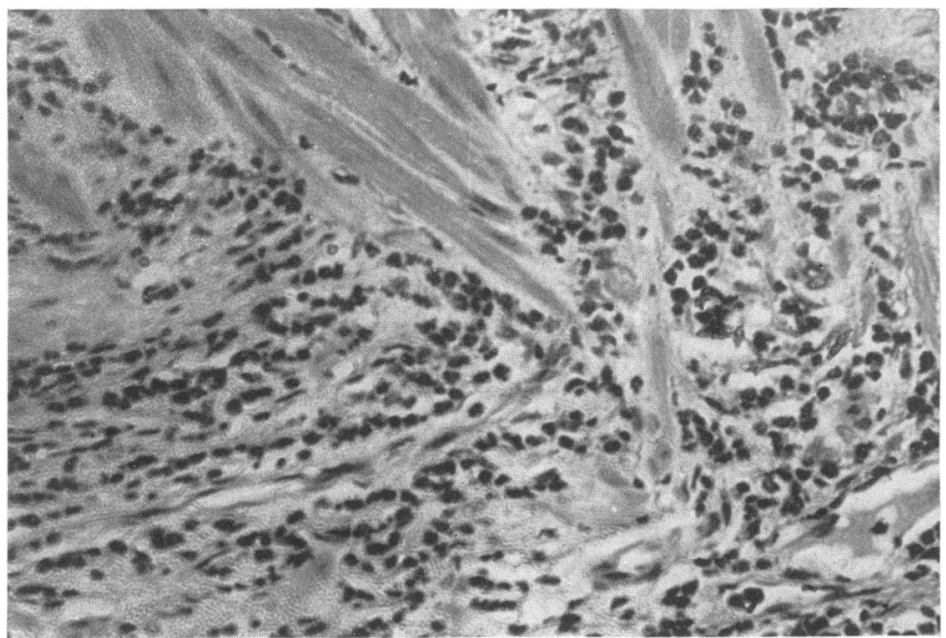

FIG. 2. Ileal biopsy showing infiltration of the muscularis by a dense infiltrate of eosinophils. The fibres are splayed with a mild interstitial oedema $(\mathrm{HE}, \times 400)$.



FIG. 3. Three months after starting treatment, appearances are virtually normal. 
Oral disodium cromoglycate was prescribed, but as the patient would only consent to a maximum of fifteen $20 \mathrm{mg}$ capsules (the only locally available strength) per $24 \mathrm{hr}$, he received a total of $300 \mathrm{mg}$ in divided doses per day. After 14 days of medication the eosinophil count was $0.378 \times 10^{9} / 1$ and IgE was $540 \mathrm{mu} . / 1$. Two months later the eosinophil count was $0.325 \times 10^{9} / 1$ and $\mathrm{IgE}$ was $240 \mathrm{mu}$./l. His weight had increased from $69 \mathrm{~kg}$ to $75 \mathrm{~kg}$ and he was asymptomatic. The serum albumin had increased to $42 \mathrm{~g} / 1$ and the alkaline phosphatase had decreased to $110 \mathrm{mmol} / \mathrm{l}$. A repeat small bowel barium study at 3 months was virtually normal (Fig. 3).

\section{Discussion}

Eosinophilic gastroenteritis, an uncommon disorder, probably occurs more often than is generally realized. Although a proportion of patients are atopic individuals and have evidence of a food allergy (Klein et al., 1970; Ureles et al., 1961) there are a number where no secondary cause such as parasites, drugs or associated vasculitis can be found. There have been reports of an association with eosinophilic infiltrations of other organs (Gregg and Utz, 1974; Rodriquez et al., 1973) but these cases may be part of the hypereosinophilic syndrome which can involve multiple organs other than the gastrointestinal tract (Chusid et al., 1975).

There is conflicting evidence on the role of food allergy. One text includes abnormal symptoms or signs following ingestion of specific foods as a criterion for diagnosis (Greenberger and Gryboski, 1978), while another concludes that hypersensitivity to food is not required in order to establish a diagnosis (Caldwell et al., 1978).

Food allergy appears to be an unlikely mechanism in this patient in view of the negative history, normal mucosa, distal involvement of the gut, negative skin tests and negative RAST. It is difficult to attribute involvement of the deeper layers to contact with allergen in the absence of mucosal involvement.

Oral sodium cromoglycate has been used in the treatment of inflammatory bowel disease (Henderson and Hishon, 1978; Mani et al., 1976), food allergy (Vaz, Tan and Gerrard, 1978) and, more recently, in gold-induced eosinophilic enterocolitis (Martin et al., 1981). However, in the latter case improvement occurred with the withdrawal of the offending agent. In the only other report of response to sodium cromoglycate in eosinophilic enteritis (Heatley, Harris and Atkinson, 1980), the patient developed polyarteritis nodosa and this may have been the disease from the outset. In both cases the patients had the mucosal form of the disorder which was secondary to another cause.

The response to the sodium cromoglycate in this patient was impressive in that there was a dramatic early fall in the long-standing eosinophilia. The $\mathbb{\otimes}$ patient gained weight, became asymptomatic and $\mathrm{a}_{\mathrm{C}}$ repeat barium study was virtually normal. It is $\rightleftharpoons$ possible that the disodium cromoglycate was either $\stackrel{\bar{s}}{\rightarrow}$ absorbed through the gut wall to act on the ab- $\overline{0}$ normal muscularis section of bowel or, alternatively, 흘 acted on the mucosal surface preventing the release $\frac{\bar{\rho}}{5}$ of mediators which act at the level of the muscularis $\stackrel{\Phi}{\Omega}$ mucosa.

This case also illustrates the difficulty encountered $\stackrel{\text { के }}{\circ}$ in diagnosing and monitoring patients whose sole $\vec{P}$ involvement is limited to the muscularis layer. In $\overrightarrow{\vec{\omega}}$ this setting conventional endoscopic biopsies and a $\stackrel{\sigma}{\sigma}$ wide range of tests for malabsorption can be com- $\overline{8}$ pletely normal. Peripheral eosinophilia can be the 3 only clue for diagnosis and therefore a simple ir differential white cell count is mandatory in all $\infty$ patients with 'obscure' abdominal complaints.

Caldwell et al. (1978) failed to demonstrate any evidence for an IgE-mediated mechanism in the $\underset{\mathcal{O}}{\mathscr{S}}$ obstructive form of eosinophilic gastroenteritis. 음 However, this case demonstrates that such mechanisms may indeed be operative in those with $D$ predominantly muscle layer involvement, and that disodium cromoglycate is of value in the IgE- $\overrightarrow{0}$ dependent group. This would be useful where the alternative therapy, corticosteroids, is inadvisable.

\section{Acknowledgment}

I am grateful to Dr H.-R. Sanders, The Medical Superintendent, Groote Schuur Hospital, for permission to report the above case.

\section{References}

Caldwell, J.H., Mekhjian, H.S., Hurtubise, P.E. \& BEMAN, F.M. (1978) Eosinophilic gastroenteritis with obstruction. Immunological studies of seven patients. Gastroenterology, 74, 825.

Chusid, M.J., Dale, D.C., West, B.C. \& Wolf, S.M. (1975) The hypereosinophilic syndrome: analysis of fourteen 3 cases with review of the literature. Medicine (Baltimore), $54,1$.

GREENBERGER, N. \& GRYBOSKI, J.D. (1978) Allergic disorders of the intestine and eosinophilic gastroenteritis. In: $\bigcirc$ Gastrointestinal Disease (Ed. by Sleisenger, M. H. \& 3 Fordtran, J. S.), 2nd edn, p. 1230. Saunders, Philadelphia. GreGG, J.A. \& UTZ, D.C. (1974) Eosinophilic cystitis associated with eosinophilic gastroenteritis. Proceedings of $D$ the Staff Meetings of the Mayo Clinic, 49, 185.

Heatley, R.V., Harris, A. \& Atkinson, M. (1980) Treatment of a patient with clinical features of both eosino- $\mathrm{N}$ philic gastroenteritis and polyarteritis nodosa with oral sodium cromoglycate. Digestive Diseases and Sciences, 25, Ð 470.

Henderson, A. \& Hishon, S. (1978) Crohn's disease res- $\omega$ ponding to oral disodium cromoglycate. Lancet, i, 109.

Klein, N.C., Hargrove, R.L., Sleisenger, M.H. \& Jef- 0 FRIES, G.H. (1970) Eosinophilic gastroenteritis. Medicine (Baltimore), 49, 299.

MANI, V., Lloyd, G., Green, F.H.Y., Fox, H. \& TuRnberg, L.A. (1976) Treatment of ulcerative colitis with oral disodium cromoglycate. A double-blind controlled trial. Lancet, i, 439. 
Martin, D.M., Goldman, J.A., Gilliam, J. \& Nasrallah, S.M. (1981) Gold-induced eosinophilic enterocolitis: response to oral cromolyn sodium. Gastroenterology, 80, 1567.

Rodriquez, J.J.V., SAez, E.S., Vega, J.S., Serrano, M.C.L. \& VAllejo, A.C. (1973) Pancreatitis and eosinophilic gastroenteritis. International Surgery, 58, 415.
Ureles, A.L., Alschibaja, T., Lodico, D. \& Stabins, S.J. (1961) Idiopathic eosinophilic infiltration of the gastrointestinal tract, diffuse and circumscribed. American Journal of Medicine, 30, 899.

VAZ, G.A., TAN, L.K.-T. \& Gerrard, J.W. (1978) Oral cromoglycate in treatment of adverse reactions to food. Lancet, i, 1066. 